Article

\title{
Biodegradation of Bisphenol A by Sphingobium sp. YC-JY1 and the Essential Role of Cytochrome P450 Monooxygenase
}

\author{
Yang Jia ${ }^{1}$, Adel Eltoukhy ${ }^{1}$, Junhuan Wang ${ }^{1}$, Xianjun Li ${ }^{1}$, Thet Su Hlaing ${ }^{1}$, Mar Mar Aung ${ }^{1}$, \\ May Thet Nwe ${ }^{1}$, Imane Lamraoui ${ }^{2}$ and Yanchun Yan ${ }^{1, *}$ \\ 1 Graduate School, Chinese Academy of Agricultural Sciences, Beijing 100081, China; \\ jia_yang@outlook.com (Y.J.); adelaly@azhar.edu.eg (A.E.); wangjunhuan@caas.cn (J.W.); \\ lixianjun1978@126.com (X.L.); thetsuhlaing11@gmail.com (T.S.H.); marmaraung1@gmail.com (M.M.A.); \\ maythetnwe1@googlemail.com (M.T.N.) \\ 2 Biotechnology Research Institute, Chinese Academy of Agricultural Sciences, Beijing 100081, China; \\ imane.lamraoui1@gmail.com \\ * Correspondence: yanyanchun@caas.cn; Tel.: +86-10-82109685
}

Received: 11 April 2020; Accepted: 8 May 2020; Published: 19 May 2020

\begin{abstract}
Bisphenol A (BPA) is a widespread pollutant threatening the ecosystem and human health. An effective BPA degrader YC-JY1 was isolated and identified as Sphingobium sp. The optimal temperature and $\mathrm{pH}$ for the degradation of BPA by strain YC-JY1 were $30^{\circ} \mathrm{C}$ and 6.5 , respectively. The biodegradation pathway was proposed based on the identification of the metabolites. The addition of cytochrome P450 (CYP) inhibitor 1-aminobenzotriazole significantly decreased the degradation of BPA by Sphingobium sp. YC-JY1. Escherichia coli BL21 (DE3) cells harboring pET28a-bisdAB achieved the ability to degrade BPA. The bisdB gene knockout strain YC-JY1 $\triangle b i s d B$ was unable to degrade BPA indicating that P450 bisdB was an essential initiator of BPA metabolism in strain YC-JY1. For BPA polluted soil remediation, strain YC-JY1 considerably stimulated biodegradation of BPA associated with the soil microbial community. These results point out that strain YC-JY1 is a promising microbe for BPA removal and possesses great application potential.
\end{abstract}

Keywords: bisphenol A; Sphingobium sp; biodegradation; cytochrome P450; soil remediation

\section{Introduction}

Bisphenol A (2, 2-bis (4-hydroxyphenyl) propane, BPA) is extensively used as a plasticizer or flame retardant in the production of synthetic polymers, such as polycarbonate plastics and epoxy resins [1-4]. The global BPA consumption closed to 7.7 million tons during 2015 and may reach 10.6 million tons by 2022. However, a quarter of the BPA was released into the environment during the process of production, transportation, or processing [5-8]. As a kind of synthetic endocrine-disrupting chemicals (EDCs), BPA would cause reproductive toxicity because of its estrogenic activity $[9,10]$. Previous studies revealed that BPA could also cause carcinogenicity [11], immunotoxicity [12], embryotoxicity [13], and transgenerational influence [14] to various species. Therefore, the elimination of BPA is essential to the ecosystem and public health.

Biodegradation of BPA by microorganisms has been proven to be a safe and economical approach to remove BPA from the environment $[3,15]$. Bacteria with the capacity to degrade several xenobiotics, including BPA, have been isolated and investigated. The first BPA degrading bacterium Sphingomonas sp. strain MV1 was isolated from the sludge of a plastic manufacturing facility [16]. BPA degrader Sphingomonas bisphenolicum strain AO1 was isolated, and the cytochrome P450 (CYP) monooxygenase gene involved in BPA degradation was investigated [17-19]. BPA degrader Sphingobium sp. BiD32 was 
isolated from activated sludge, and a $p$-hydroxybenzoate hydroxylase was hypothesized to be involved in BPA degradation [20]. Besides, several bacteria with biodegradation ability of BPA were isolated and explored, such as Achromobacter xylosoxidans strain B-16, Cupriavidus basilensis strain JF1, C. basilensis strain SBUG 290, and Novosphingobium sp. TYA-1 [21-24]. Although BPA degradation pathways have been extensively studied, the knowledge of metabolic mechanisms, including catalysts and genes, was still limited. Fungi and some nonspecific fungal enzymes were demonstrated to attack BPA, such as lignin peroxidase, laccases, manganese peroxidases, and versatile peroxidases [25-27]. CYP monooxygenases are a superfamily of enzymes that may be involved in the metabolism of xenobiotics. It was reported that $b i s d A$ and $b i s d B$ genes encoding ferredoxin and cytochrome P450 were responsible for BPA degradation in Sphingomonas bisphenolicum strain AO1 [17,19]. Extracellular laccases produced by some Pseudomonas showed BPA transformation capacity [28]. An ammonia monooxygenase in Nitrosomonas europaea was reported to be involved in BPA degradation [29]. Although some various biodegradation pathways information has emerged, the further efforts of genetic basis and mechanisms are imperative.

In the present study, a new BPA degrading bacterial strain Sphingobium sp. YC-JY1, which could utilize BPA as a sole carbon and energy source, was isolated and characterized. The biodegradation conditions were optimized, and the degradation pathway was proposed by detecting the degradation intermediates via high-performance liquid chromatography-quadrupole-time-of-flight tandem mass spectrometry (HPLC-QTOF-MS/MS). Furthermore, cytochrome P450 was heterogeneously expressed, and strain YC-JY1 $\triangle b i s d B$ was constructed to explore the role of the cytochrome P450 gene. In addition, the capacity of YC-JY1 to remediate BPA-contaminated soil was investigated.

\section{Results and Discussion}

\subsection{Strain Isolation and Identification}

One strain capable of degrading BPA with high performance was isolated from the sludge samples by enrichment culture technique. Strain YC-JY1 degraded $100 \mathrm{mg} / \mathrm{L}$ BPA completely within $12 \mathrm{~h}$ under the condition of $30^{\circ} \mathrm{C}$ and $\mathrm{pH} 7.0$ (Figure 1a). The strain was rod-shaped with apical flagellum (Figure 1b). The16S rRNA gene sequences of strain YC-JY1 and other related type strains were used to construct the phylogenetic tree to identify strain YC-JY1. The neighbor-joining method was adopted for phylogenetic analysis. The phylogenetic tree (Figure 1c) showed that this strain was clustered with strain Sphingobium yanoikuyae ATCC 51230. The result of Biolog GEN III microplate testing (Table S1) showed that it may be in the same species with Sphingobium paucimobilis B. Therefore, it suggested that strain YC-JY1 belongs to the genus Sphingobium, thus it was named as Sphingobium sp. YC-JY1. Several BPA-degrading bacteria have been isolated and investigated by researchers (Table 1). Most of the isolated BPA-degrading bacteria showed degradation activity at low concentration, and they took several days to degrade. Sphingobium sp. YC-JY1 completely degraded $100 \mathrm{mg} / \mathrm{L}$ BPA as sole carbon and energy source within $12 \mathrm{~h}$. Obviously, Sphingobium sp. YC-JY1 was an excellent BPA-degrader with the ability to degrade a high concentration of BPA efficiently. 
(a)

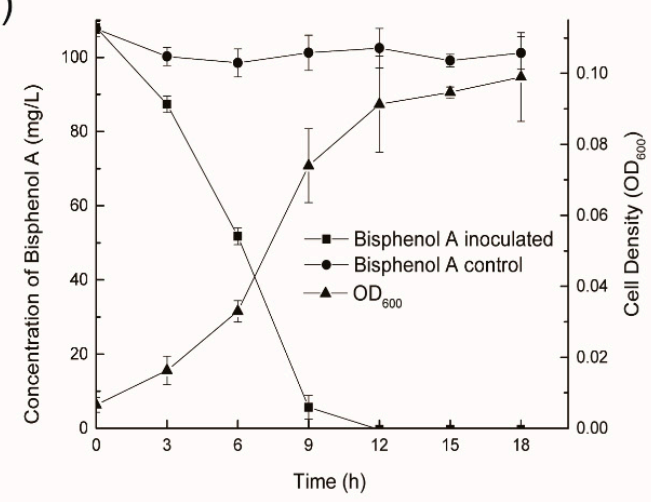

(b)

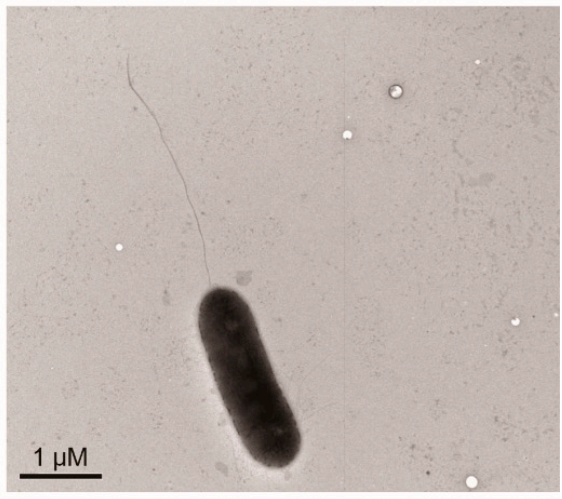

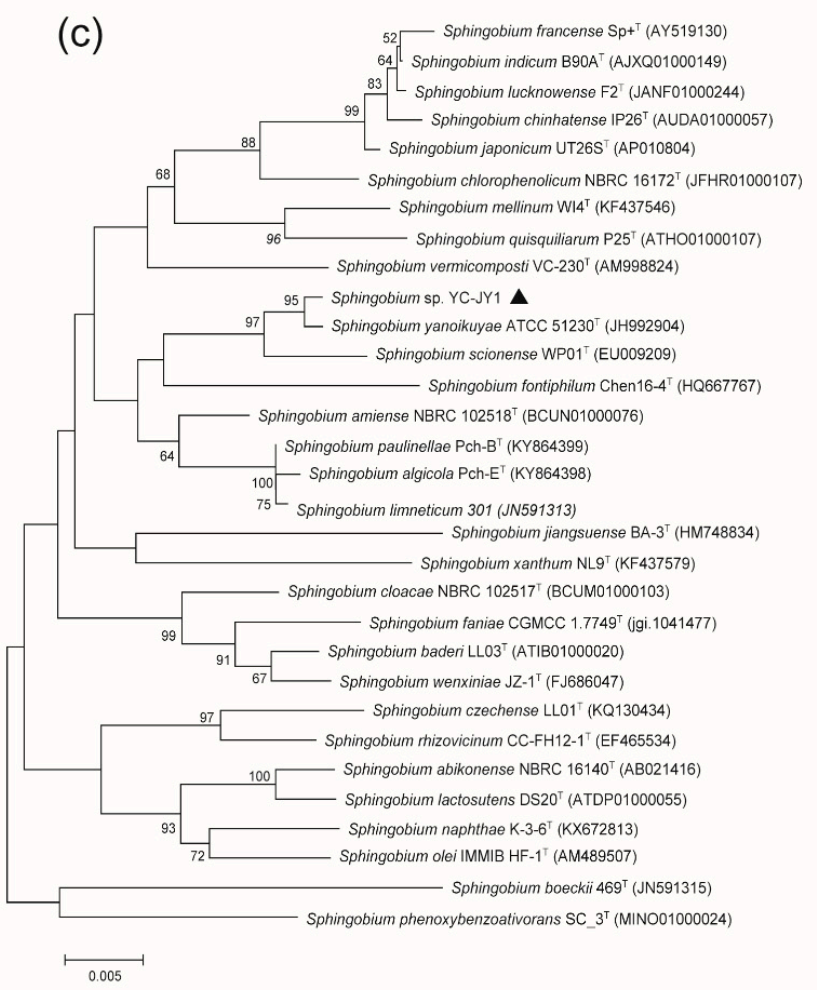

Figure 1. (a) Bisphenol A (BPA) degradation by strain YC-JY1 and growth curve. (b) The morphological characteristics of strain YC-JY1 observed by a transmission electron microscope. (c) Phylogenetic tree based on 16S rRNA gene sequence analysis of strain YC-JY1 and other Sphingobium genus strains. Sphingobium sp. YC-JY1 was marked using a dark triangle.

Table 1. Biodegradation of BPA by various microorganisms.

\begin{tabular}{cccc}
\hline Microorganism & Resources & Degradation Efficiency & References \\
\hline Sphingomonas sp. strain MV1 & sludge & $100 \%, 10 \mathrm{~g} / \mathrm{L}, 4$ days & {$[16]$} \\
Sphingomonas bisphenolicum strain & & $100 \%, 115 \mathrm{mg} / \mathrm{L}, 117 \mathrm{~h}($ without & {$[18]$} \\
AO1 & soil & other carbon sources); & \\
Achromobacter xylosoxidans B-16 & wastes compost leachate & $100 \%, 115 \mathrm{mg} / \mathrm{L}, 6 \mathrm{~h}$ (with glucose) & {$[21]$} \\
Sphingomonas sp. strain BP-7 & offshore seawater & $>900 \%, 3 \mathrm{mg} / \mathrm{L}, 4.5$ days & {$[30]$} \\
Cupriavidus basilensis JF1 & fixed bed reactor & $50 \%, 34.2 \mathrm{mg} / \mathrm{L}, 140$ days & {$[23]$} \\
Bacillus sp. GZB & sediment & $92.9 \%, 5 \mathrm{mg} / \mathrm{L}, 96 \mathrm{~h}$ & {$[9]$} \\
Sphingobium sp. BiD32 & sludge & $100 \%, 1 \mathrm{mg} / \mathrm{L}, 4.2 \mathrm{~h}$ & {$[31]$} \\
Nitrosomonas europaea ATCC 19718 & NR ${ }^{1}$ & $>50 \%, 1 \mathrm{mg} / \mathrm{L}, 5$ days & {$[32]$} \\
\hline
\end{tabular}

\footnotetext{
${ }^{1}$ NR means not reported.
} 


\subsection{Effects of Environmental Factors on Biodegradation of BPA}

The temperature, $\mathrm{pH}$, inoculum density, and $\mathrm{NaCl}$ concentration are important factors influencing biodegradation significantly [9,33-35]. These factors not only impact on metabolism and growth of microorganisms, but also on the enzyme activity [36,37]. The effect of temperature on BPA biodegradation was shown in Figure 2a. The results indicated that the degradation efficiency increased with rising temperatures ranging from 15 to $30^{\circ} \mathrm{C}$, reached the maximum level at $30^{\circ} \mathrm{C}$ and then the degradation efficiency gradually decreased with higher temperatures. The degradation efficiencies after $12 \mathrm{~h}$ incubation were $40.8 \% 78.4 \%, 99 \%, 100 \%$, and $83.3 \%$ at the temperatures of $15,20,25,30$, and $35^{\circ} \mathrm{C}$, respectively. The degradation efficiencies of $100 \mathrm{mg} / \mathrm{L}$ BPA after $9 \mathrm{~h}$ of incubation were $22.4 \%\left(15^{\circ} \mathrm{C}\right), 44 \%\left(20^{\circ} \mathrm{C}\right), 66.9 \%\left(25^{\circ} \mathrm{C}\right), 97.1 \%\left(30^{\circ} \mathrm{C}\right)$, and $49.5 \%\left(35^{\circ} \mathrm{C}\right)$. No degradation of BPA was observed at $40{ }^{\circ} \mathrm{C}$, while the slightly increased concentration might be due to the evaporation of water. The result was in agreement with previous studies that higher temperatures within a certain range accelerated the degradation $[9,21]$.
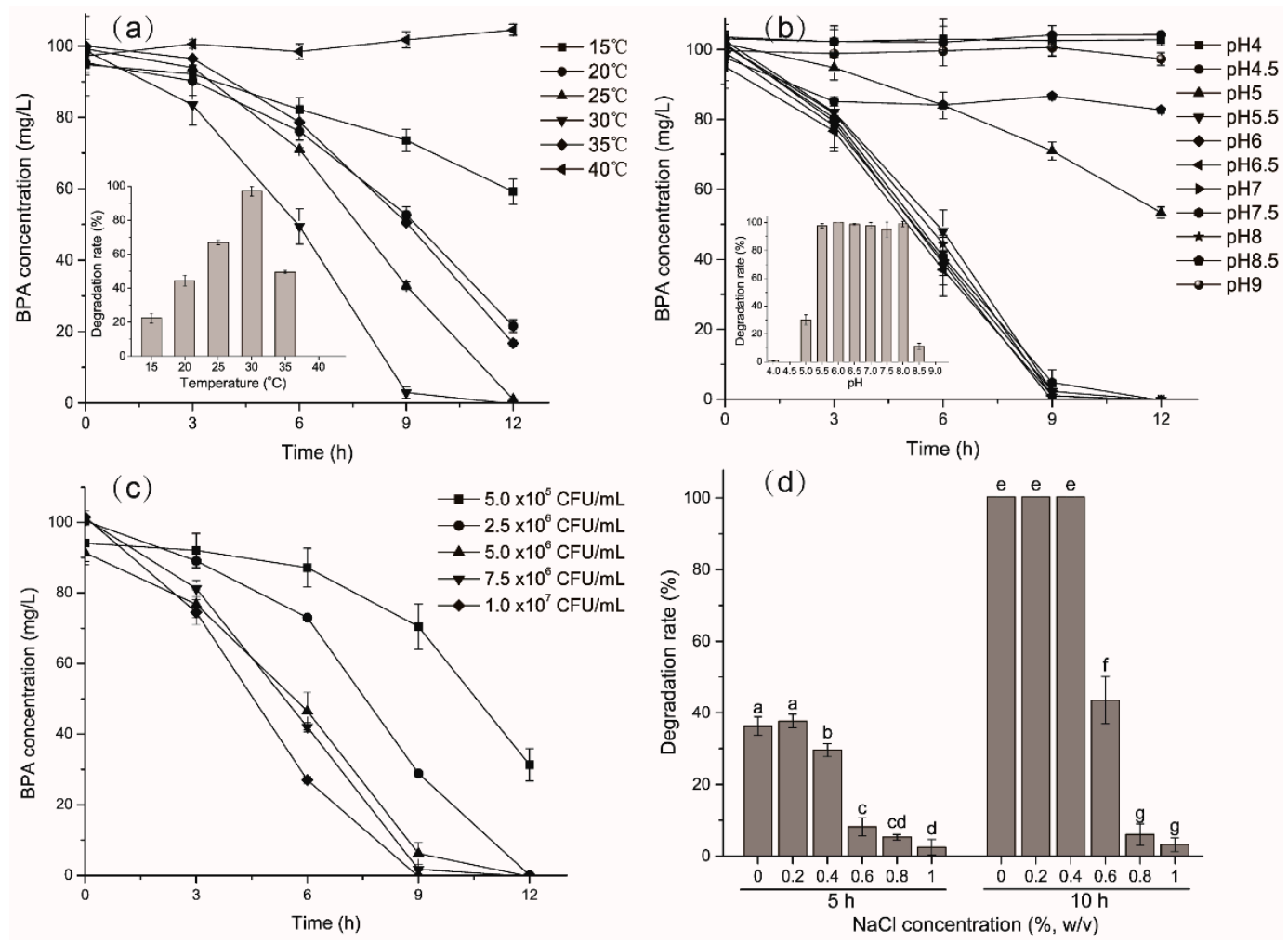

Figure 2. Effect of (a) temperature; (b) $\mathrm{pH}$; (c) inoculums density and (d) $\mathrm{NaCl}$ concentration on biodegradation of BPA. The error bar value presents the standard deviation of triplicates. Inset shows BPA biodegradation efficiency at $9 \mathrm{~h}$ on different (a) temperature and (b) $\mathrm{pH}$ value. Different letters indicate statistically significant differences at $p \leq 0.05$; similarly hereinafter.

To detect the optimum $\mathrm{pH}$ value for BPA degradation by YC-JY1, $11 \mathrm{pH}$ values from 4 to 9 were examined. The degradation efficiencies were $100 \%$ ranging from $\mathrm{pH} 5.5$ to 8 after $12 \mathrm{~h}$ of incubation (Figure 2b). YC-JY1 showed decent degradation ability under both weak acidic and alkaline conditions, although BPA would be with low solubility in weak acidic conditions, and the bacterial growth and enzyme activity would be inhibited under weak alkaline condition.

Inoculums density would also affect the degradation of BPA. With the inoculum size from $5.0 \times 10^{5} \mathrm{CFU} / \mathrm{mL}$ to $1.0 \times 10^{7} \mathrm{CFU} / \mathrm{mL}$, BPA was finished within $12 \mathrm{~h}$ while the degradation efficiency was $68.7 \%$ with the inoculum size of $5.0 \times 10^{5} \mathrm{CFU} / \mathrm{mL}$. The degradation efficiencies of $100 \mathrm{mg} / \mathrm{L}$ BPA after $9 \mathrm{~h}$ of incubation were $29.5 \%, 71.1 \%, 93.8 \%, 98.3 \%$, and $100 \%$ with inoculum size $5.0 \times 10^{5} \mathrm{CFU} / \mathrm{mL}$, $2.5 \times 10^{6} \mathrm{CFU} / \mathrm{mL}, 5.0 \times 10^{6} \mathrm{CFU} / \mathrm{mL}, 7.5 \times 10^{6} \mathrm{CFU} / \mathrm{mL}$ and $1.0 \times 10^{7} \mathrm{CFU} / \mathrm{mL}$, respectively (Figure $2 \mathrm{c}$ ). 
These results indicated that higher cell density would increase the biodegradation efficiency, which was in accord with previous researches showing a synergistic effect of the biomass amount on biodegradation of BPA $[9,21,38,39]$.

Salinity is another environmental factor that impacts biodegradation efficiency. In this study, $\mathrm{NaCl}$ concentrations ranging from $0 \%$ to $1 \%(w / v)$ were examined, and degradation efficiencies were determined after $5 \mathrm{~h}$ and $10 \mathrm{~h}$ incubation (Figure 2d). At $5 \mathrm{~h}$, BPA biodegradation efficiency was not affected at $0.2 \% \mathrm{NaCl}$ concentration but decreased at $0.4 \% \mathrm{NaCl}$ concentration. At higher $\mathrm{NaCl}$ concentration s ( $0.6 \%$ to $1 \%)$, biodegradation was significantly inhibited. At $10 \mathrm{~h}$, BPA was completely biodegraded at $0 \%$ to $0.4 \% \mathrm{NaCl}$ concentration, and degradation efficiency decreased extremely at higher $\mathrm{NaCl}$ concentration. These results showed the degradation efficiencies were inhibited by adding $\mathrm{NaCl}$, indicating that $\mathrm{NaCl}$ was a disadvantage of degradation.

\subsection{Identification of Metabolites}

To interpret the BPA biodegradation pathways and metabolic mechanisms in YC-JY1, HPLC-QTOF-MS/MS was employed to detect the metabolites. Intermediates of BPA biodegradation were identified with retention times of $3.873 \mathrm{~min}$ (2,3-bis(4-hydroxyphenyl)-1,2-propanediol, 3,4-BP, $m / z 259.098[\mathrm{M}-\mathrm{H}]^{-}$)(A), 5.709 min (4-hydroxybenzaldehyde, 4-HBD, $m / z 121.03[\mathrm{M}-\mathrm{H}]^{-}$) (B), $5.946 \mathrm{~min}\left(4^{\prime}\right.$-hydroxyacetophenone, 4-HAP, $\left.\mathrm{m} / z 135.046[\mathrm{M}-\mathrm{H}]^{-}\right)(\mathrm{C}), 7.203 \mathrm{~min}(1,2$-bis $(4-$ hydroxyphenyl)-2-propanol, 1-BP, $m / z 243.103[\mathrm{M}-\mathrm{H}]^{-}$) (D), $12.236 \mathrm{~min}\left(\mathrm{BPA}, \mathrm{m} / \mathrm{z} 227.108[\mathrm{M}-\mathrm{H}]^{-}\right.$) (E), 15.560 min (4,4'-dihydroxy- $\alpha$-methylstilbene, 4-DM, $\left.m / z 225.092[\mathrm{M}-\mathrm{H}]^{-}\right)$(F) (Figure S1). These proposed products were shown in Table 2. The proposed products 4-HAP and 4-HBD were verified using standards. 4-HAP and 4-HBD could be utilized by strain YC-JY1 as a sole carbon source, separately (data not shown). As time went on, a new peak with retention times of $6.89 \mathrm{~min}\left(\mathrm{~m} / \mathrm{z} 211.077[\mathrm{M}-\mathrm{H}]^{-}\right)$ appeared in the sample after incubation for $9 \mathrm{~h}$. After $24 \mathrm{~h}$ incubation, three peaks accumulated with retention time $3.873 \mathrm{~min}\left(\mathrm{~m} / \mathrm{z} 259.098[\mathrm{M}-\mathrm{H}]^{-}\right), 6.89 \mathrm{~min}\left(\mathrm{~m} / \mathrm{z} 211.077[\mathrm{M}-\mathrm{H}]^{-}\right), 8.086 \mathrm{~min}(\mathrm{~m} / z 213.056$ $\left.[\mathrm{M}-\mathrm{H}]^{-}\right)$. These substances were unknown.

Table 2. Degradation metabolites of BPA by strain YC-JY1 using HPLC-QTOF-MS/MS.

\begin{tabular}{|c|c|c|c|c|c|}
\hline Proposed Products & RT (min) & $\mathbf{M}(m / z)$ & $\begin{array}{l}\text { MS/MS } \\
(m / z)\end{array}$ & $\begin{array}{l}\text { Molecular } \\
\text { Formula }\end{array}$ & Structure \\
\hline $\begin{array}{l}\text { 1,2-Bis(4-hydroxyphenyl)-2- } \\
\text { propanol }\end{array}$ & 7.171 7.212 & 243 & $\begin{array}{l}135,210 \\
225\end{array}$ & $\mathrm{C}_{15} \mathrm{H}_{16} \mathrm{O}_{3}$ & \\
\hline $\begin{array}{l}\text { 4, } 4^{\prime} \text {-Dihydroxy- } \alpha- \\
\text { methylstilbene }\end{array}$ & $15.557 \sim 15.565$ & 225 & 69 & $\mathrm{C}_{15} \mathrm{H}_{14} \mathrm{O}_{2}$ & \\
\hline 4-Hydroxybenzaldehyde & $5.700 \sim 5.709$ & 121 & 92 & $\mathrm{C}_{7} \mathrm{H}_{6} \mathrm{O}_{2}$ & \\
\hline $4^{\prime}$-Hydroxyacetophenone & $5.931 \sim 5.947$ & 135 & 92,120 & $\mathrm{C}_{8} \mathrm{H}_{8} \mathrm{O}_{2}$ & \\
\hline $\begin{array}{l}\text { 2,3-Bis(4-hydroxyphenyl)-1,2- } \\
\text { propanediol }\end{array}$ & $3.839 \sim 3.873$ & 259 & 62,135 & $\mathrm{C}_{15} \mathrm{H}_{16} \mathrm{O}_{4}$ & \\
\hline
\end{tabular}

The strategy of the microbial transformation of BPA is diverse. Mycobacterium sp. transformed BPA by O-methylation into monomethyl and dimethyl ethers [40]. Sasaki et al. identified metabolites of BPA by GC-MS or LC-MS-MS, and the results indicated that 4-DM, 4-HAP, and 1-BP or 2-BP (2,2-bis(4-hydroxyphenyl)-1-propanol) were involved in the biodegradation pathway [18]. The metabolic pathway of BPA degradation in Achromobacter xylosoxidans strain B-16 was proposed according to the intermediates ( $p$-hydroxybenzaldehyde, $p$-hydroxybenzoic acid, and $p$-hydroquinone) [21]. Based on nine identified intermediates, pathways of BPA degradation by 
spore laccase of Bacillus sp. GZB was proposed [41]. According to the identified metabolites and literature surveys, the metabolic degradation pathway of BPA by strain YC-JY1 was proposed, as shown in Figure 3. It was speculated that there were two routes in strain YC-JY1 to degrade BPA. In one pathway, BPA was converted into 1-BP, and then it was converted via 4-DM into 4-HBD and 4-HAP, which were then utilized by strain YC-JY1. In the other pathway, BPA was converted to 2-BP and then 3,4-BP. And 3,4-BP was accumulated in the medium. These results have a good consistency with some reports, and these intermediates also emerged in the processes of photocatalytic degradation and biotransformation of BPA [9].

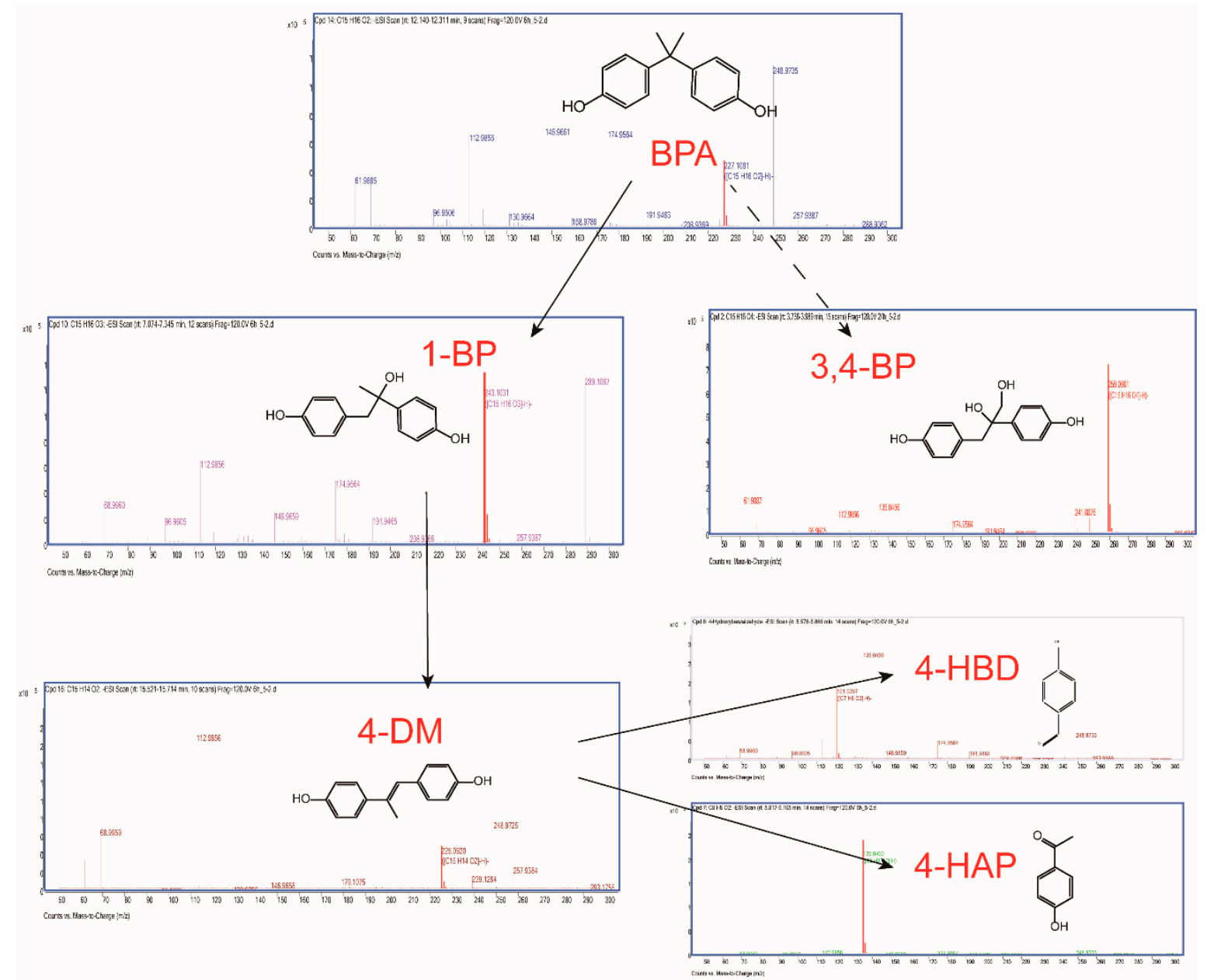

Figure 3. Proposed biodegradation pathway of BPA in Sphingobium sp. YC-JY1 based on HPLC-QTOF-MS/MS. BPA, bisphenol A; 1-BP, 1,2-Bis(4-hydroxyphenyl)-2-propanol; 3,4-BP, 2,3-Bis(4-hydroxyphenyl)-1,2-propanediol; 4-DM, 4,4'-Dihydroxy- $\alpha$-methylstilbene; 4-HBD, 4Hydroxybenzaldehyde; 4-HAP, 4'-Hydroxyacetophenone.

\subsection{Effect of Cytochrome P450 Inhibitor and BPA Degradation Activity of Cytochrome P450}

1-aminobenzotriazole (ABT), a common inhibitor of CYP, was used to reduce the activity of CYP. It is often used to demonstrate whether a reaction is catalyzed by CYP enzymes [42-44]. In the presence of $0.1,0.5,1$, and $2 \mathrm{mmol} / \mathrm{L} \mathrm{ABT}, 46.8 \%, 12 \%, 6.5 \%$, and $3.4 \%$ of BPA disappeared after $9 \mathrm{~h}$ of incubation, respectively, compared to $85.5 \%$ in cultures without ABT (Figure 4). ABT significantly inhibited BPA degradation, and the degradation efficiency decreased when $\mathrm{ABT}$ concentration rising, indicating that CYP was related to BPA degradation in strain YC-JY1. These findings indicated that the CYP is responsible for BPA degradation, which is in accord with some researches showing the involvement of CYP in xenobiotics transformation $[37,44]$. The presence of ABT demonstrated a slight decrease in 
BPA removal rate for Chaetomium strumarium G5I, Thielavia arenaria $\mathrm{CH} 9$, Thielavia arenaria $\mathrm{HJ} 22$ and Thielavia arenaria SM1(III), suggesting the effective contribution of CYP in the conversion [44].

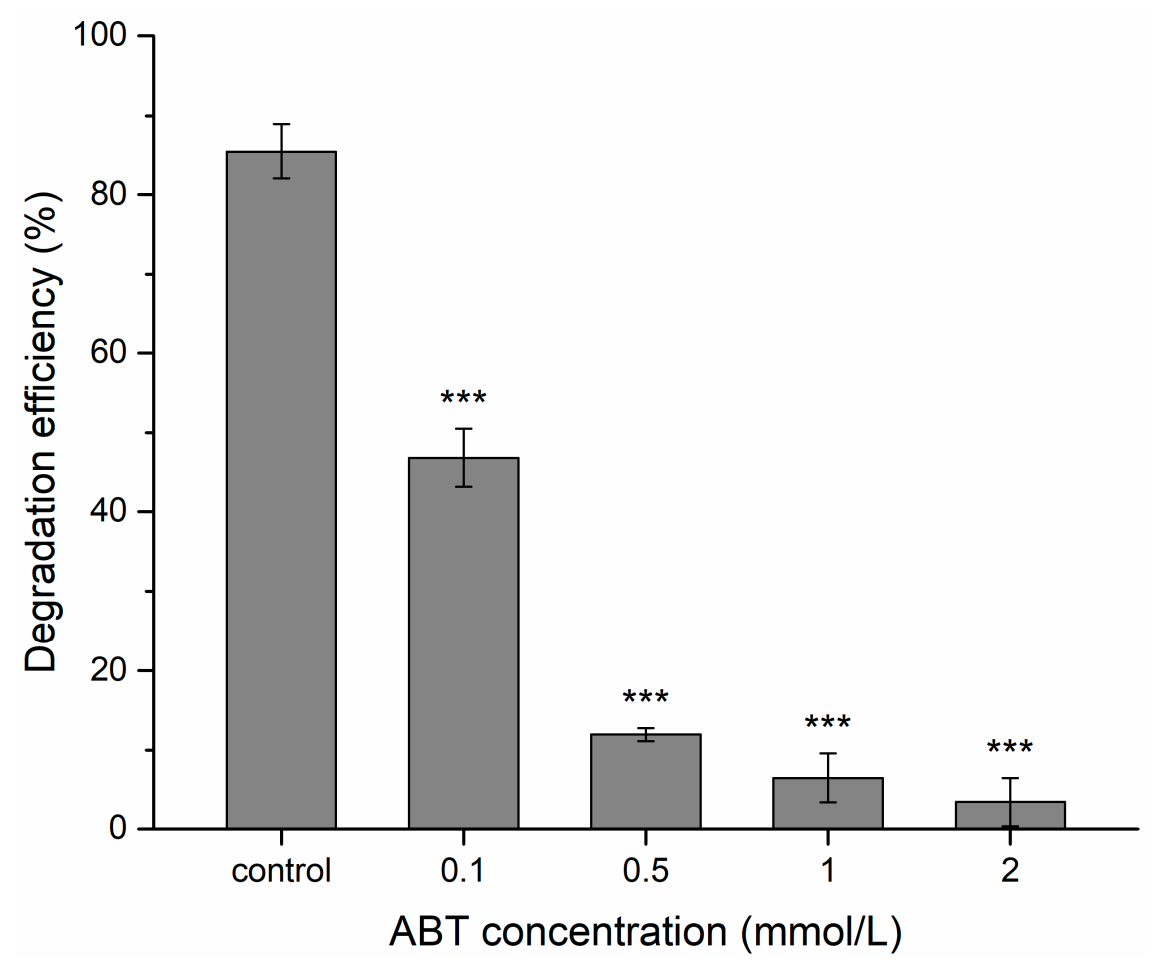

Figure 4. Effect of cytochrome P450 inhibitor ABT on BPA degradation by Sphingobium sp. YC-JY1 after $9 \mathrm{~h}$ of incubation. ${ }^{* *} p<0.001$ indicates an extremely significant difference compared to the control.

Sasaki et al. discovered that CYP, encoded by bisd in Sphingomonas bisphenolicum AO1 had the ability to degrade BPA. Based on genome sequence analysis, the bisdA and bisdB genes were cloned from YC-JY1. Phylogenetic analysis of P450 bisdB encoded by bisdB gene of strain YC-JY1 and other bacterial cytochrome P450s is shown in Figure 5. P450 bisdB was clustered with $\mathrm{P}^{4} 50_{\text {bisdB }}$ from Sphingomonas bisphenolicum $\mathrm{AO} 1$ and showed high similarity $(97.9 \%)$. $\mathrm{P}^{4} 50_{\text {bisdB }}$ showed very low similarity with other P450s. The complete amino acid sequences of BisdA and BisdB proteins encoded by bisdA and bisdB genes of strain YC-JY1 were shown in the supplementary data, and the motifs of them were identified.
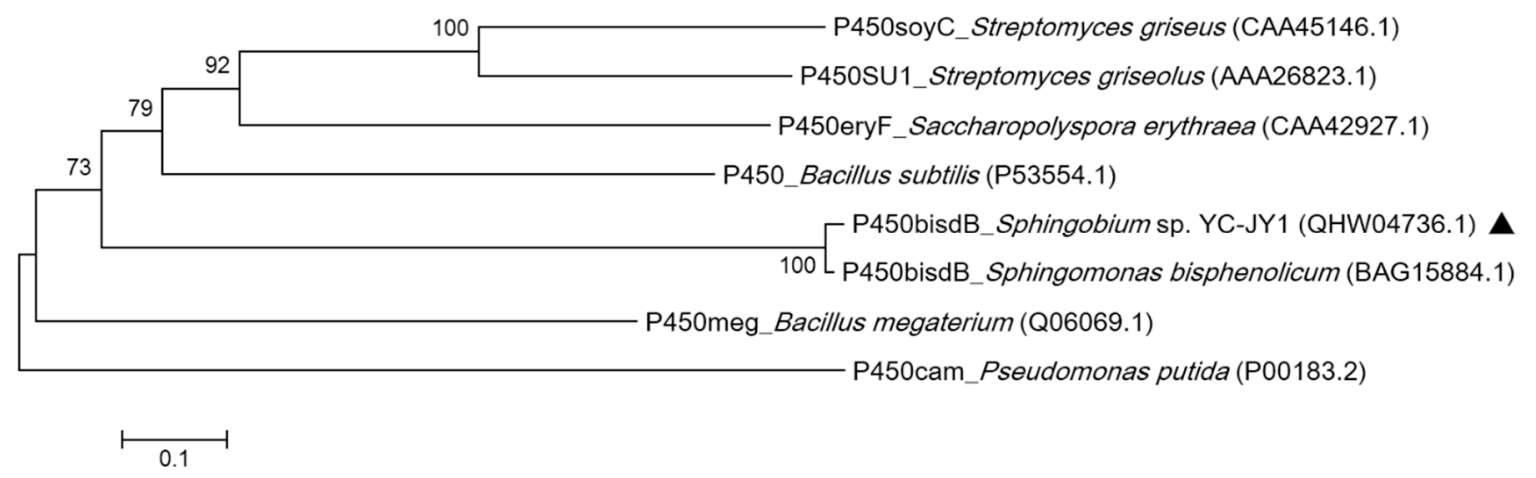

Figure 5. Phylogenetic analysis of P450 bisdB from strain YC-JY1 and other bacterial cytochrome P450 proteins. The phylogenetic tree was constructed by the neighbor-joining method using MEGA 5.2 software. P450 bisdB from Sphingobium sp. YC-JY1 was marked using a dark triangle. The accession numbers of the protein sequences were in brackets.

E. coli has been known to have some ferredoxins and ferredoxin reductases, flavodoxin, and flavodoxin reductases, which are needed by active P450s. It indicated that $E$. coli cells bearing bis $d B$ 
might get the capacity of BPA degradation [19]. Consequently, the BPA-degradation capacity of E. coli BL21 (DE3) cells bearing pET28-bisdB or pET28-bisdAB, respectively, in LB medium supplied with BPA was investigated.

BL21(DE3)-pET28a-bisdB cells converted less than $10 \mathrm{mg} / \mathrm{L}$ BPA after $24 \mathrm{~h}$ incubation with addition of IPTG, whereas BL21(DE3)-pET28a-bis $d A B$ cells degraded about $85 \mathrm{mg} / \mathrm{L}$ BPA. While E. coli cells bearing $b i s d B-$, bis $d A B$ - without the addition of IPTG showed no BPA degradation capacity (Figure 6). It was opposite to the research results of Sasaki et al., stating BPA-degradation capacity decreased when IPTG was added into the medium [19]. Besides, ferredoxin of YC-JY1 was key for BPA degradation by $\mathrm{P} 450_{\text {bisdB }}$, while the ferredoxin of E. coli could not meet the requirement well. The ferredoxin reductases of E. coli contributed to the degradation. However, activities of $\mathrm{P}^{4} 50_{b i s d B}$ were not detected in the cell lysates (data not shown), indicating this recombinant $\mathrm{P} 450_{\text {bisdB }}$ may be in an unstable or inactive form, and the cells provided a relatively suitable environment for the reaction. A more appropriate expression system for $\mathrm{P}^{4} 50_{\text {bisdB }}$ was required. The metabolites of BPA transformed by E. coli cells bearing bisdAB were detected using HPLC-QTOF-MS/MS. 4-HBD, 4-HAP, 1-BP, 2-BP were identified in the metabolites (Figure S2). These results supported the proposed pathway via metabolites analysis.

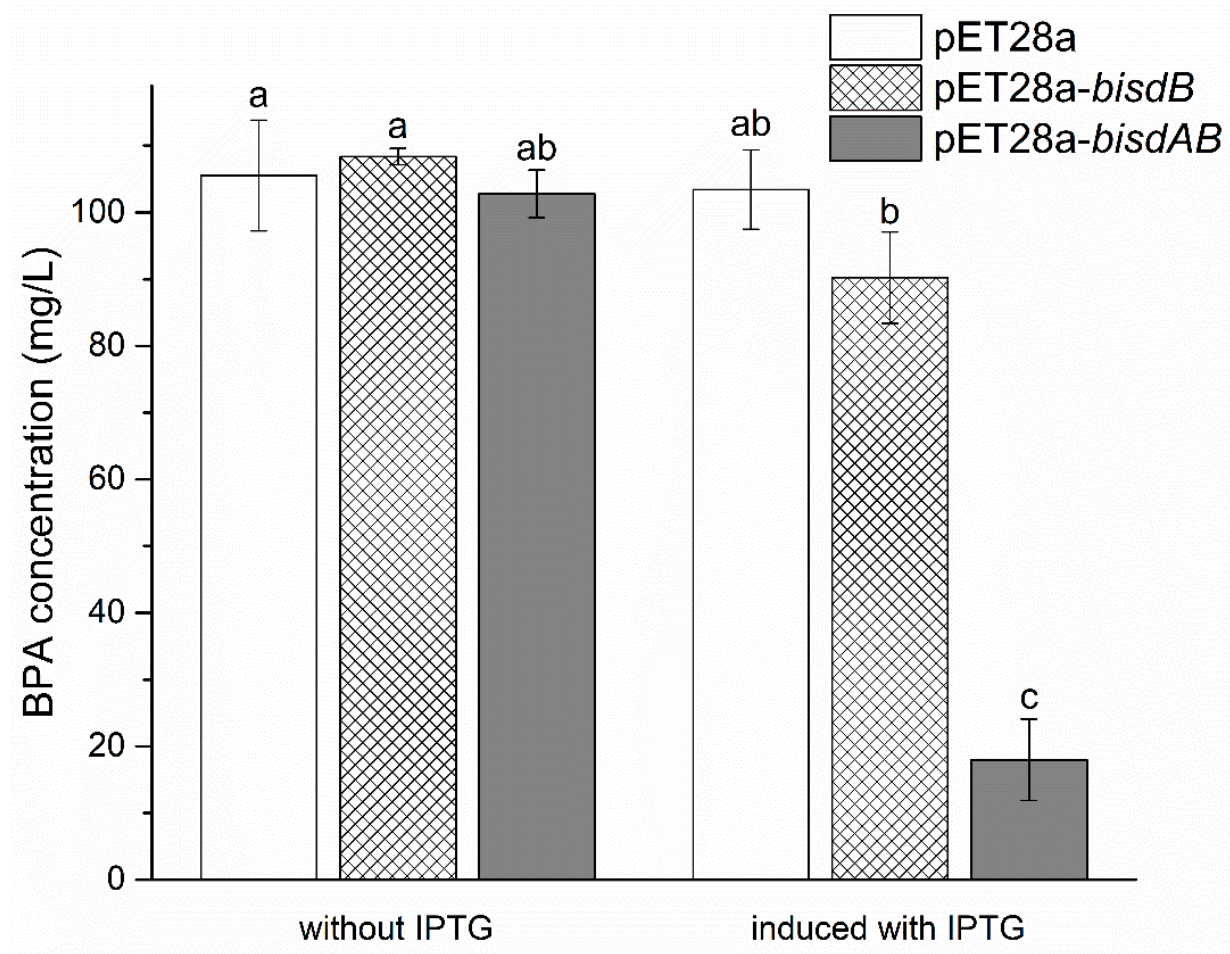

Figure 6. BPA degradation by pET28-bis $d B$ and pET28-bisdAB recombinant cells after $24 \mathrm{~h}$ of incubation in Luria-Bertani (LB) medium. The different letters $(\mathrm{a}-\mathrm{c})$ represent significant differences at $p \leq 0.05$.

\subsection{Essential Role of CYP Gene for BPA Degradation in Strain YC-JY1}

Since P450 bisdB has shown to be able to remove BPA, it is curious to test whether YC-JY1 could metabolize BPA without the bisdB gene. A spontaneous mutant of strain $\mathrm{AO} 1$ without the bisd $A B$ region lost the BPA degradation ability [19]. However, that cannot be ruled out by the influence of other lost genes. Thus, a knockout strain was constructed to test the role of bisdB in the BPA metabolism of strain YC-JY1. Strain YC-JY1 $\Delta b i s d B$, which grew as well as YC-JY1 in the LB medium, lost its ability of BPA degradation in the TEM medium (Figure S3) with no visible growth, implying that the bisdB gene is essential for the catabolism of BPA and it initiated the degradation of BPA in strain. Knockout of bisdB intuitively and rigorously demonstrated the importance of $b i s d B$ in the degradation process of BPA. 


\subsection{Effect of Inoculated YC-JY1 on Remediation of BPA-Contaminated Soil}

The microbial inoculation of strain YC-JY1 in BPA-contaminated soils was conducted to explore the influence of strain YC-JY1 on moderating BPA contamination. Results showed that strain YC-JY1 possessed strong soil remediation capabilities. As shown in Figure 7, the residual amount of BPA was $29.5 \mathrm{mg} / \mathrm{kg}$ (unsterilized group) and $35.4 \mathrm{mg} / \mathrm{kg}$ (sterilized group) after inoculating $5.0 \times 10^{7} \mathrm{CFU} / \mathrm{g}$ YC-JY1 and incubating for 2 days. In both groups, BPA residues decreased with the increase of the inoculum amount and BPA residues in the unsterilized group were significantly less than that in the corresponding sterilized group, implying that, there may be some indigenous BPA degraders or an associated metabolism between YC-JY1 and resident microbiota. The soil environment is so complex that the degradation efficiency would be affected by many aspects, e.g., soil constitution, humidity content, microbial species, etc. Cooperative metabolism in microbial communities or consortia would promote biodegradation efficiency compared with the biodegrading bacterium alone [45]. Microbial interaction metabolism based on the cross-feeding with intermediates of the BPA degradation was a considerable factor for soil remediation. The cooperation enabled the microbial community to efficiently utilize carbon and energy from BPA [45]. It has been reported that supplementation with Sphingomonas bisphenolicum AO1 was able to significantly improve the BPA decomposition activity of the microbial community in soil [46]. Pseudomonas sp. BP-14, Pseudomonas sp. BP-15, and strain No. 24A without BPA degradation ability could accelerate the degradation of BPA by Sphingomonas sp. BP-7 [30]. During the initial phase of BPA degradation, inoculated strain YC-JY1 with CYP would play a dominant role, while other microbes, which lacked genes responsible for initial BPA degradation but possessed the lower pathway of BPA degradation, would promote the transformation process. This cooperative substrate cross-feeding between BPA-degrading microbes and non-degrading microbes accelerated the pollutant removal in the environment. Based on its potential application, strain YC-JY1 is expected to be a candidate as a biodegradable cleanser for environmental remediation.

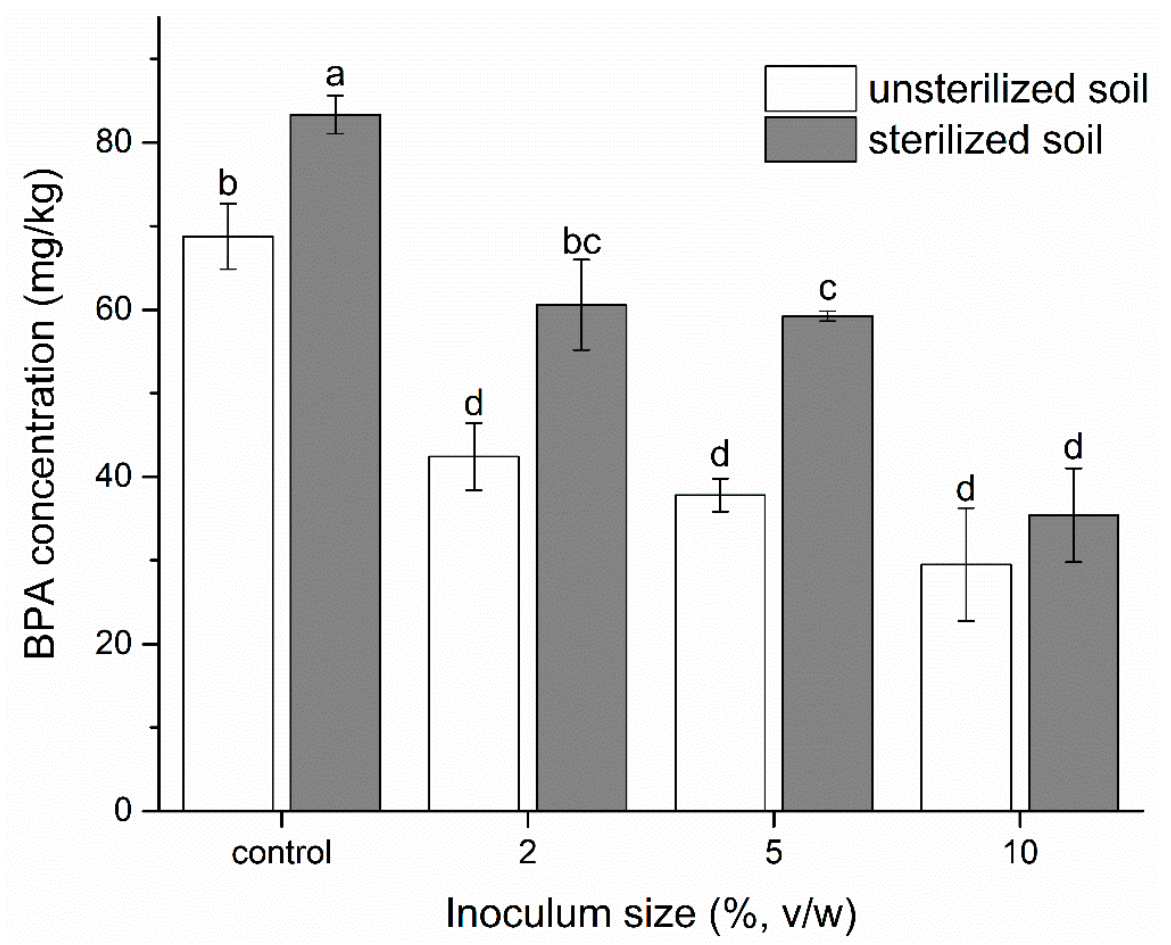

Figure 7. Decontamination of BPA-contaminated soil by inoculating Sphingobium sp. YC-JY1. The different letters $(\mathrm{a}-\mathrm{d})$ represent significant differences at $p \leq 0.05$. 


\section{Materials and Methods}

\subsection{Chemicals and Medium}

Bisphenol A (BPA) (>99\% purity) was purchased from Shanghai Macklin Biochemical Co., Ltd. 1-aminobenzotriazole (ABT) (98\% purity) was from J\&K Scientific. HPLC grade acetonitrile was from Thermo Fisher Scientific Inc. Trace element medium (TEM) and Luria-Bertani (LB) medium were used for enrichment and purification of isolated bacteria and bacteria culture. The detailed information of media was shown in the supplementary data. The $\mathrm{pH}$ was adjusted to approximately 7 , and agar $(1.6 \%)$ was added into LB and TEM media to prepare solid media. The media were sterilized at $121^{\circ} \mathrm{C}$ for $20 \mathrm{~min}$. Antibiotics were added to the medium as necessary.

\subsection{Strain Isolation and Identification}

The sludge sample was collected from a river in Guangdong Province, China $\left(23^{\circ} 17^{\prime} 53.38^{\prime \prime} \mathrm{N}\right.$ $116^{\circ} 20^{\prime} 21.41^{\prime \prime} \mathrm{E}$ ). The TEM medium containing BPA (range from $50 \mathrm{mg} / \mathrm{L}$ to $300 \mathrm{mg} / \mathrm{L}$ ) was used for enrichment and purification of BPA degradation strain. Approximately $5 \mathrm{~g}$ of soil was added into $50 \mathrm{~mL}$ TEM medium in a $250 \mathrm{~mL}$-Erlenmeyer flask, supplied with $50 \mathrm{mg} / \mathrm{L}$ of BPA. The culture was incubated at $180 \mathrm{rpm}$ and $30{ }^{\circ} \mathrm{C}$ for 5 days. $5 \mathrm{~mL}$ of the culture was transferred into $50 \mathrm{~mL}$ fresh TEM medium with $100 \mathrm{mg} / \mathrm{L} \mathrm{BPA}$. These steps were further repeated 4 times until the BPA concentration reached $300 \mathrm{mg} / \mathrm{L}$ (BPA concentration increased $50 \mathrm{mg} / \mathrm{L}$ each time).

Strain YC-JY1, which showed an excellent capability to degrade BPA was isolated. The cells of YC-JY1 were observed using a transmission electron microscope. It was identified using the Biolog GEN III microplate protocol. The detailed information of the protocol was shown in the supplementary data. The partial 16S rRNA gene was amplified by polymerase chain reaction (PCR) with the universal primers 27F and 1492R (Table S2). BLAST was employed for homology search, and 16S rRNA gene sequences of standard bacterial strains were downloaded from a List of Prokaryotic names with Standing in Nomenclature (LPSN, http://www.bacterio.net/). The phylogenetic tree was built to analyze the evolution using MEGA (version 5.2, Tempe, AZ, USA).

\subsection{Preparation of the Bacterial Suspension}

Strain YC-JY1 was pre-cultured in LB medium at $30{ }^{\circ} \mathrm{C}$ for $12 \mathrm{~h}$, harvested by centrifugation at $5000 \mathrm{rpm}$ for $5 \mathrm{~min}$ and then washed twice with TEM medium. The bacteria were then resuspended in TEM medium to set optical density at $600 \mathrm{~nm}\left(\mathrm{OD}_{600}\right)$ of 0.8 . Colony-forming units $(\mathrm{CFU} / \mathrm{mL})$ of this suspension were quantified by the dilution plate count technique. For batch experiments, $100 \mu \mathrm{L}$ of the suspension was inoculated into $10 \mathrm{ml}$ of TEM with BPA to obtain a final cell density of approximately $5.0 \times 10^{6} \mathrm{CFU} / \mathrm{mL}$ for BPA biodegradation following studies.

\subsection{Effects of Environmental Factors on BPA Biodegradation}

To investigate the impacts of environmental factors on the degradation of BPA, a series of batch experiments about temperature, $\mathrm{pH}$, inoculum density, and $\mathrm{NaCl}$ concentration were conducted. The incubation temperatures were set as $15-40{ }^{\circ} \mathrm{C}$ at $\mathrm{pH}$. The initial $\mathrm{pH}$ of the TEM medium was adjusted to $4-9$ at $30^{\circ} \mathrm{C}$. Inoculum size $\left(5.0 \times 10^{5} \mathrm{CFU} / \mathrm{mL}\right.$ to $\left.1.0 \times 10^{7} \mathrm{CFU} / \mathrm{mL}\right)$ and $\mathrm{NaCl}$ concentration $(0 \%-1 \%, w / v)$ were carried out at $30{ }^{\circ} \mathrm{C}, \mathrm{pH}$ 7. The incubation was performed in $50 \mathrm{~mL}$-Erlenmeyer flasks at $180 \mathrm{rpm}$ in the dark. BPA residues in culture media were detected by high-performance liquid chromatography (HPLC) (Agilent 1200, Palo Alto, CA, USA).

\subsection{Identification of Metabolites}

To investigate the BPA degradation pathway in strain YC-JY1, the BPA metabolites after incubating for $0 \mathrm{~h}, 3 \mathrm{~h}, 6 \mathrm{~h}, 9 \mathrm{~h}, 12 \mathrm{~h}$, and $24 \mathrm{~h}$ were analyzed. The cell cultures $(10 \mathrm{~mL})$ were extracted twice using an equal volume of ethyl acetate and then concentrated by rotary evaporator (R-215, Buchi, 
Switzerland). The residues were dissolved in $500 \mu \mathrm{L}$ HPLC-grade acetonitrile and filtered using $0.22 \mu \mathrm{m}$ membrane (Millipore, Bedford, MA, USA) for analysis. HPLC-QTOF-MS/MS (Agilent 6500, Agilent 6545, Palo Alto, CA, USA) was employed to detect the samples.

\subsection{Cytochrome P450 Inhibitor Experiment}

ABT was used as a CYP inhibitor to investigate the role of CYP in BPA degradation in this study. ABT was added into TEM medium, and final ABT concentrations were 0.1, 0.5, 1, and $2 \mathrm{mmol} / \mathrm{L}$, respectively. Then, strain YC-JY1 was pre-incubated with ABT for $2 \mathrm{~h}$, followed by the addition of BPA $(100 \mathrm{mg} / \mathrm{L})$. These cultures were further incubated for $9 \mathrm{~h}$, and BPA residues were measured by HPLC. The cultures without ABT were served as control. Each treatment was conducted in triplicate.

\subsection{Cloning and Expression of bisdB and bisdAB}

The genomic DNA of strain YC-JY1 was extracted using a bacterial genomic DNA extraction kit (TaKaRa, Dalian, China). Based on genome sequence analysis of strain YC-JY1, potential BPA degradation genes $b i s d A$ and $b i s d B$ were proposed. Gene bis $d B$ was amplified with primers bisdB-F and bisdB-R. The bisdAB fragment was amplified from strain YC-JY1 using primers bisdAB-F, bisdAB-R (Table S2). The PCR products were purified using a DNA fragment purification kit (TaKaRa) and ligated into the pET28a(+) vectors after digestion to obtain the plasmids pET28a-bisdB and pET28a-bisdAB. The plasmids were then transformed into E. coli BL21(DE3). BPA transformation products by $E$. coli (pET28a-bisdAB) were analyzed using HPLC-QTOF-MS/MS.

\subsection{Gene Knockout of bisdB}

Plasmid pEX18Tc-bisdB for gene knockout was constructed by fusing PCR products of the kanamycin resistance gene (kan), an upstream fragment (uf) of bisdB gene amplified with primers bisdBup-F and bisdBup-R, and a downstream fragment ( $\mathrm{df}$ ) amplified with primers bisdBdown-F and bisdBdown-R to the EcoR I and Hind III digested pEX18Tc using the Uni Seamless Cloning and Assembly Kit (Transgen, Beijing, China). The plasmid with uf-kan-df fragment was then transformed into E. coli SM10 $\lambda$ pir before its conjugation with strain YC-JY1. The double-crossover recombinants of strain YC-JY1 $\triangle b i s d B$ were screened on LB plates containing nitrofurantoin, kanamycin, and $15 \%$ $(w / v)$ sucrose.

\subsection{Remediation of BPA-Contaminated Soil}

The effects of inoculated strain YC-JY1 on BPA residues in soil were evaluated. The soil collected from the garden was air-dried and sieved $(0.45 \mathrm{~mm})$. The soil experiment was set in 2 groups (unsterilized and sterilized soil). All soils were spiked with $100 \mathrm{mg} / \mathrm{kg}$ BPA and inoculated with a different final cell density of strain YC-JY1 as following, $0 \mathrm{CFU} / \mathrm{g}, 1.0 \times 10^{7} \mathrm{CFU} / \mathrm{g}, 2.5 \times 10^{7} \mathrm{CFU} / \mathrm{g}$ and $5.0 \times 10^{7} \mathrm{CFU} / \mathrm{g}$. These treatments were conducted in triplicate and incubated at $30^{\circ} \mathrm{C}$ for 2 days in the dark. BPA residues were extracted from the soil using $10 \mathrm{~mL}$ acetonitrile shaking in the dark for $2 \mathrm{~h}$. Then the samples were placed in $4^{\circ} \mathrm{C}$ for $2 \mathrm{~h}$. The BPA residues were detected by HPLC.

\subsection{Analytical Methods and Statistical Analysis}

Cell growth was measured as $\mathrm{OD}_{600}$ by a UV-Visible spectrophotometer (Thermo Scientific, Wilmington, DE, USA). The concentration of BPA was detected by HPLC (Agilent 1200, USA) equipped with an Eclipse XDB-C18 column $(4.6 \times 150 \mathrm{~mm}, 5 \mu \mathrm{m})$ and a visible ultraviolet detector. The mobile phase was acetonotrile and $0.1 \%$ formic acid in water (70:30). The flow rate was $1 \mathrm{~mL} / \mathrm{min}$ with an injection volume of $2 \mu \mathrm{L}$ and detecting wavelength of $220 \mathrm{~nm}$.

An Agilent 6500 HPLC system and Agilent 6545 QTOF mass spectrometer equipped with an Eclipse XDB-C18 column $(4.6 \times 150 \mathrm{~mm}, 5 \mu \mathrm{m})$ were used to detect the metabolites of BPA. The mobile phase was acetonitrile (A) and $0.1 \%$ formic acid in water (B). A gradient run was used as follows: 
0-5 min, 30\% A; 5-6 min, 30-50\% A; 6-11 min, 50\% A; 11-12 min, 50-70\% A; 12-13 min 70-90\% A; 13-18 $\mathrm{min}, 90 \% \mathrm{~A} ; 18-20 \mathrm{~min}, 90-50 \% \mathrm{~A} ; 20-22 \mathrm{~min}, 50-30 \% \mathrm{~A} ; 22-25 \mathrm{~min}, 30 \% \mathrm{~A}$. The flow rate was $0.5 \mathrm{~mL} / \mathrm{min}$ with an injection volume of $2 \mu \mathrm{L}$. The column oven temperature was maintained at $30{ }^{\circ} \mathrm{C}$. The ESI ion source was operated in negative mode. Operation conditions were set as follows: The gas temperature was $325^{\circ} \mathrm{C}$; gas flow was $6 \mathrm{~L} / \mathrm{min}$; nebulizer pressure was $35 \mathrm{psig}$; sheath gas temperature was $350^{\circ} \mathrm{C}$; sheath gas flow was $11 \mathrm{~L} / \mathrm{min}$; scan model and negative ions in the mass range of 50 to $500 \mathrm{~m} / \mathrm{z}$ was adopted; capillary voltage was 3.5 kV. Mass Hunter (version B.07.00, Agilent, Palo Alto, CA, USA) was employed to analyze the data.

The data analyses were performed by $t$-test using SPSS software (version 20, Chicago, IL, USA). The statistical significance was accepted at $p<0.05$.

\subsection{Accession Numbers}

The 16S rRNA gene sequence of Sphingobium sp. YC-JY1 was deposited in Genbank under the accession number MN165536. The bisdA and bisdB gene sequences were deposited in Genbank with access number MN171527. Strain YC-JY1 was deposited in the China General Microbiological Culture Collection Center (Beijing, China) under the accession CGMCC No. 16352.

\section{Conclusions}

An efficient BPA-biodegrading bacterium Sphingobium sp. YC-JY1 was isolated and identified. The BPA degradation efficiency was affected by a few factors (e.g., temperature, $\mathrm{pH}$, inoculum size, and $\mathrm{NaCl}$ concentration). The biodegradation pathway was proposed based on the analysis of the metabolites. It was certified that $\mathrm{P} 450_{b i s d B}$ was the essential initiator for BPA metabolism in strain YC-JY1. Strain YC-JY1 considerably stimulated biodegradation of BPA in BPA-contaminated soil, showing YC-JY1 is a potential candidate for remediation of the BPA-contaminated environment.

Supplementary Materials: Supplementary materials can be found at http://www.mdpi.com/1422-0067/21/10/ 3588/s1, Table S1: Layout of assays for MicroPlate (GEN III). Table S2: Strains, plasmids, and primers used in this study. Figure S1: HPLC-TOF-MS/MS chromatograms of intermediates during the biodegradation of BPA from $0 \mathrm{~h}$ to $24 \mathrm{~h}$. Figure S2: The chromatogram and mass spectra of primary ions for BPA degradation by E. coli (pET28a-bisd $A B$ ) intermediates analyzed by HPLC-TOF-MS/MS. Figure S3: BPA degradation by strain YC-JY1 and strain YC-JY1 $\triangle b i s d B$ in TEM medium.

Author Contributions: Formal analysis, Y.J.; funding acquisition, Y.Y.; investigation, Y.J., A.E., J.W., and X.L.; methodology, Y.Y.; project administration, Y.Y.; writing-original draft, Y.J.; writing-review and editing, Y.J., T.S.H., M.M.A., M.T.N., and I.L. All authors have read and agreed to the published version of the manuscript.

Funding: This work was supported by the National Natural Science Foundation of China [No. 31540067, 21876201] and the Basic Research Fund of the Chinese Academy of Agricultural Sciences [No. 1610042017001, 1610042018005, and 1610042018006].

Conflicts of Interest: The authors declare no conflict of interest.

\section{References}

1. Kamaraj, M.; Sivaraj, R.; Venckatesh, R. Biodegradation of Bisphenol A by the tolerant bacterial species isolated from coastal regions of Chennai, Tamil Nadu, India. Int. Biodeterior. Biodegrad. 2014, 93, $216-222$. [CrossRef]

2. Yassine, O.; Mehdi, Z.; Patrick, D.; Brahima, S.; Gerardo, B.; Rino, D. Performance of a membrane bioreactor in extreme concentrations of bisphenol A. Water Sci. Technol. 2018, 77, 1505-1513.

3. Fu, M.; Xing, J.; Ge, Z. Preparation of laccase-loaded magnetic nanoflowers and their recycling for efficient degradation of bisphenol A. Sci. Total Environ. 2019, 651, 2857-2865. [CrossRef] [PubMed]

4. Olajuyigbe, F.M.; Adetuyi, O.Y.; Fatokun, C.O. Characterization of free and immobilized laccase from Cyberlindnera fabianii and application in degradation of bisphenol A. Int. J. Biol. Macromol. 2019, 125, 856-864. [CrossRef] [PubMed] 
5. Mohapatra, D.P.; Brar, S.K.; Tyagi, R.D.; Surampalli, R.Y. Physico-chemical pre-treatment and biotransformation of wastewater and wastewater sludge-fate of bisphenol A. Chemosphere 2010, 78, 923-941. [CrossRef]

6. Huang, Y.Q.; Wong, C.K.; Zheng, J.S.; Bouwman, H.; Barra, R.; Wahlstrom, B.; Neretin, L.; Wong, M.H. Bisphenol A (BPA) in China: A review of sources, environmental levels, and potential human health impacts. Environ. Int. 2012, 42, 91-99. [CrossRef]

7. Eio, E.J.; Kawai, M.; Tsuchiya, K.; Yamamoto, S.; Toda, T. Biodegradation of bisphenol A by bacterial consortia. Int. Biodeterior. Biodegrad. 2014, 96, 166-173. [CrossRef]

8. de Freitas, E.N.; Bubna, G.A.; Brugnari, T.; Kato, C.G.; Nolli, M.; Rauen, T.G.; de Fátima Peralta Muniz Moreira, R.; Peralta, R.A.; Bracht, A.; de Souza, C.G.M.; et al. Removal of bisphenol A by laccases from Pleurotus ostreatus and Pleurotus pulmonarius and evaluation of ecotoxicity of degradation products. Chem. Eng. J. 2017, 330, 1361-1369. [CrossRef]

9. Li, G.; Zu, L.; Wong, P.K.; Hui, X.; Lu, Y.; Xiong, J.; An, T. Biodegradation and detoxification of bisphenol A with one newly-isolated strain Bacillus sp. GZB: Kinetics, mechanism and estrogenic transition. Bioresource Technol. 2012, 114, 224-230. [CrossRef]

10. Suyamud, B.; Inthorn, D.; Panyapinyopol, B.; Thiravetyan, P. Biodegradation of bisphenol a by a newly isolated Bacillus megaterium strain ISO-2 from a polycarbonate industrial wastewater. Water Air Soil Poll. 2018, 229, 229-348. [CrossRef]

11. Haighton, L.A.; Hlywka, J.J.; Doull, J.; Kroes, R.; Lynch, B.S.; Munro, I.C. An evaluation of the possible carcinogenicity of bisphenol A to humans. Regul. Toxicol. Pharm. 2002, 35, 238-254. [CrossRef] [PubMed]

12. Nowak, K.; Jablonska, E.; Ratajczak-Wrona, W. Immunomodulatory effects of synthetic endocrine disrupting chemicals on the development and functions of human immune cells. Environ. Int. 2019, 125, 350-364. [CrossRef] [PubMed]

13. Zhou, R.; Cheng, W.; Feng, Y.; Wei, H.; Liang, F.; Wang, Y. Interactions between three typical endocrine-disrupting chemicals (EDCs) in binary mixtures exposure on myocardial differentiation of mouse embryonic stem cell. Chemosphere 2017, 178, 378-383. [CrossRef] [PubMed]

14. Berger, A.; Ziv-Gal, A.; Cudiamat, J.; Wang, W.; Zhou, C.; Flaws, J.A. The effects of in utero bisphenol A exposure on the ovaries in multiple generations of mice. Reprod. Toxicol. 2016, 60, 39-52. [CrossRef]

15. Eltoukhy, A.; Jia, Y.; Nahurira, R.; Abo-Kadoum, M.A.; Khokhar, I.; Wang, J.; Yan, Y. Biodegradation of endocrine disruptor Bisphenol A by Pseudomonas putida strain YC-AE1 isolated from polluted soil, Guangdong, China. BMC Microbiol. 2020, 20, 11. [CrossRef]

16. Lobos, J.H.; Leib, T.K.; Su, T.M. Biodegradation of bisphenol A and other bisphenols by a gram-negative aerobic bacterium. Appl. Environ. Microbiol. 1992, 58, 1823-1831. [CrossRef]

17. Sasaki, M.; Akahira, A.; Oshiman, K.; Tsuchido, T.; Matsumura, Y. Purification of cytochrome P450 and ferredoxin, involved in bisphenol A degradation, from Sphingomonas sp. strain AO1. Appl. Environ. Microbiol. 2005, 71, 8024-8030. [CrossRef]

18. Sasaki, M.; Maki, J.; Oshiman, K.; Matsumura, Y.; Tsuchido, T. Biodegradation of bisphenol A by cells and cell lysate from Sphingomonas sp. strain AO1. Biodegradation 2005, 16, 449-459. [CrossRef]

19. Sasaki, M.; Tsuchido, T.; Matsumura, Y. Molecular cloning and characterization of cytochrome P450 and ferredoxin genes involved in bisphenol A degradation in Sphingomonas bisphenolicum strain AO1. J. Appl. Microbiol. 2008, 105, 1158-1169. [CrossRef]

20. Zhou, N.A.; Kjeldal, H.; Gough, H.L.; Nielsen, J.L. Identification of Putative Genes Involved in Bisphenol A Degradation Using Differential Protein Abundance Analysis of Sphingobium sp. BiD32. Environ. Sci. Technol. 2015, 49, 12232-12241. [CrossRef]

21. Zhang, C.; Zeng, G.; Yuan, L.; Yu, J.; Li, J.; Huang, G.; Xi, B.; Liu, H. Aerobic degradation of bisphenol A by Achromobacter xylosoxidans strain B-16 isolated from compost leachate of municipal solid waste. Chemosphere 2007, 68, 181-190. [CrossRef]

22. Toyama, T.; Sato, Y.; Inoue, D.; Sei, K.; Chang, Y.C.; Kikuchi, S.; Ike, M. Biodegradation of bisphenol A and bisphenol $\mathrm{F}$ in the rhizosphere sediment of Phragmites australis. J. Biosci. Bioeng. 2009, 108, 147-150. [CrossRef] [PubMed]

23. Fischer, J.; Kappelmeyer, U.; Kastner, M.; Schauer, F.; Heipieper, H.J. The degradation of bisphenol A by the newly isolated bacterium Cupriavidus basilensis JF1 can be enhanced by biostimulation with phenol. Int. Biodeterior. Biodegrad. 2010, 64, 324-330. [CrossRef] 
24. Zuhlke, M.K.; Schluter, R.; Mikolasch, A.; Zuhlke, D.; Giersberg, M.; Schindler, H.; Henning, A.K.; Frenzel, H.; Hammer, E.; Lalk, M.; et al. Biotransformation and reduction of estrogenicity of bisphenol A by the biphenyl-degrading Cupriavidus basilensis. Appl. Microbiol. Biotechnol. 2017, 101, 3743-3758. [CrossRef] [PubMed]

25. Tsutsumi, Y.; Haneda, T.; Nishida, T. Removal of estrogenic activities of bisphenol A and nonylphenol by oxidative enzymes from lignin-degrading basidiomycetes. Chemosphere 2001, 42, 271-276. [CrossRef]

26. Galliker, P.; Hommes, G.; Schlosser, D.; Corvini, P.F.; Shahgaldian, P. Laccase-modified silica nanoparticles efficiently catalyze the transformation of phenolic compounds. J. Colloid Interf. Sci. 2010, 349, 98-105. [CrossRef]

27. Cajthaml, T. Biodegradation of endocrine-disrupting compounds by ligninolytic fungi: Mechanisms involved in the degradation. Environ. Microbiol. 2015, 17, 4822-4834. [CrossRef]

28. Telke, A.A.; Kalyani, D.C.; Jadhav, U.U.; Parshetti, G.K.; Govindwar, S.P. Purification and characterization of an extracellular laccase from a Pseudomonas sp. LBC1 and its application for the removal of bisphenol A. J. Mol. Catal. B Enzym. 2009, 61, 252-260. [CrossRef]

29. Roh, H.; Subramanya, N.; Zhao, F.; Yu, C.P.; Sandt, J.; Chu, K.H. Biodegradation potential of wastewater micropollutants by ammonia-oxidizing bacteria. Chemosphere 2009, 77, 1084-1089. [CrossRef]

30. Sakai, K.; Yamanaka, H.; Moriyoshi, K.; Ohmoto, T.; Ohe, T. Biodegradation of bisphenol a and related compounds by Sphingomonas sp. strain BP-7 isolated from seawater. Biosci. Biotech. Bioch. 2007, 71, 51-57. [CrossRef]

31. Zhou, N.A.; Lutovsky, A.C.; Andaker, G.L.; Gough, H.L.; Ferguson, J.F. Cultivation and characterization of bacterial isolates capable of degrading pharmaceutical and personal care products for improved removal in activated sludge wastewater treatment. Biodegradation 2013, 24, 813-827. [CrossRef] [PubMed]

32. Sun, Q.; Li, Y.; Chou, P.H.; Peng, P.Y.; Yu, C.P. Transformation of bisphenol A and alkylphenols by ammonia-oxidizing bacteria through nitration. Environ. Sci. Technol. 2012, 46, 4442-4448. [CrossRef] [PubMed]

33. Ren, L.; Jia, Y.; Ruth, N.; Shi, Y.; Wang, J.; Qiao, C.; Yan, Y. Biotransformations of bisphenols mediated by a novel Arthrobacter sp. strain YC-RL1. Appl. Microbiol. Biotechnol. 2016, 100, 1967-1976. [CrossRef] [PubMed]

34. Nahurira, R.; Ren, L.; Song, J.; Jia, Y.; Wang, J.; Fan, S.; Wang, H.; Yan, Y. Degradation of Di(2-Ethylhexyl) Phthalate by a Novel Gordonia alkanivorans Strain YC-RL2. Curr. Microbiol. 2017, 74, 309-319. [CrossRef] [PubMed]

35. Yang, T.; Ren, L. Biodegradation of Di-(2-ethylhexyl) Phthalate by Rhodococcus ruber YC-YT1 in Contaminated Water and Soil. Int. J. Environ. Res. Public Health 2018, 15, 964. [CrossRef]

36. Zeng, J.; Zhu, Q.; Wu, Y.; Lin, X. Oxidation of polycyclic aromatic hydrocarbons using Bacillus subtilis CotA with high laccase activity and copper independence. Chemosphere 2016, 148, 1-7. [CrossRef]

37. Wei, K.; Yin, H.; Peng, H.; Lu, G.; Dang, Z. Bioremediation of triphenyl phosphate by Brevibacillus brevis: Degradation characteristics and role of cytochrome P450 monooxygenase. Sci. Total Environ. 2018, 627, 1389-1395. [CrossRef]

38. Kang, J.H.; Kondo, F. Effects of bacterial counts and temperature on the biodegradation of bisphenol A in river water. Chemosphere 2002, 49, 493-498. [CrossRef]

39. Boonyaroj, V.; Chiemchaisri, C.; Chiemchaisri, W.; Theepharaksapan, S.; Yamamoto, K. Toxic organic micro-pollutants removal mechanisms in long-term operated membrane bioreactor treating municipal solid waste leachate. Bioresour. Technol. 2012, 113, 174-180. [CrossRef]

40. McCormick, J.M.; Van Es, T.; Cooper, K.R.; White, L.A.; Haggblom, M.M. Microbially mediated O-methylation of bisphenol A results in metabolites with increased toxicity to the developing zebrafish (Danio rerio) embryo. Environ. Sci. Technol. 2011, 45, 6567-6574. [CrossRef]

41. Das, R.; Li, G.; Mai, B.; An, T. Spore cells from BPA degrading bacteria Bacillus sp. GZB displaying high laccase activity and stability for BPA degradation. Sci. Total Environ. 2018, 640-641, 798-806. [CrossRef] [PubMed]

42. Rappert, S.; Li, R.; Kokova, M.; Antholz, M.; Nagorny, S.; Francke, W.; Muller, R. Degradation of 2,5-dimethylpyrazine by Rhodococcus erythropolis strain DP-45 isolated from a waste gas treatment plant of a fishmeal processing company. Biodegradation 2007, 18, 585-596. [CrossRef] [PubMed]

43. Ning, D.; Wang, H.; Zhuang, Y. Induction of functional cytochrome P450 and its involvement in degradation of benzoic acid by Phanerochaete chrysosporium. Biodegradation 2010, 21, 297-308. [CrossRef] [PubMed] 
44. Mtibaa, R.; Olicon-Hernandez, D.R.; Pozo, C.; Nasri, M.; Mechichi, T.; Gonzalez, J.; Aranda, E. Degradation of bisphenol A and acute toxicity reduction by different thermo-tolerant ascomycete strains isolated from arid soils. Ecotoxicol. Environ. Saf. 2018, 156, 87-96. [CrossRef]

45. Yu, K.; Yi, S.; Li, B.; Guo, F.; Peng, X.; Wang, Z.; Wu, Y.; Alvarez-Cohen, L.; Zhang, T. An integrated meta-omics approach reveals substrates involved in synergistic interactions in a bisphenol A (BPA)-degrading microbial community. Microbiome 2019, 7, 16. [CrossRef]

46. Matsumura, Y.; Akahira-Moriya, A.; Sasaki-Mori, M. Bioremediation of bisphenol-A polluted soil by Sphingomonas bisphenolicum AO1 and the microbial community existing in the soil. Biocontrol Sci. 2015, 20, 35-42. [CrossRef]

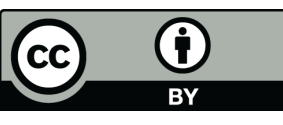

(C) 2020 by the authors. Licensee MDPI, Basel, Switzerland. This article is an open access article distributed under the terms and conditions of the Creative Commons Attribution (CC BY) license (http://creativecommons.org/licenses/by/4.0/). 